\title{
Water-Demand Growth Modelling in Puerto Ayora's Water Distribution Network Using EPANET
}

\author{
María Reyes* \\ Environmental Engineering and Water Technology Department, IHE Delft (Institute for Water Education), Netherlands \\ Nemanja Trifunović \\ Environmental Engineering and Water Technology Department, IHE Delft (Institute for Water Education), Netherlands \\ Saroj Sharma \\ Environmental Engineering and Water Technology Department, IHE Delft (Institute for Water Education), Netherlands \\ Maria Kennedy \\ Environmental Engineering and Water Technology Department, IHE Delft (Institute for Water Education), Netherlands \\ Faculty of Civil Engineering and Geosciences, Delft University of Technology, The Netherlands, Netherlands
}

\begin{abstract}
This paper elaborates the hydraulic characteristics of the water supply network of the town of Puerto Ayora. First, it intends to replicate the household individual storage by simulating nodal tanks with the use of the EPANET software. Later, it uses the Pressure-Driven Approach (PDA) to develop a methodology that estimates the overflow of storage facilities, one of the main sources of wastage in Puerto Ayora. Finally, it uses the Demand-Driven Approach (DDA), with the aim of assessing the network in the future, under four population growth scenarios. With the chosen moderate growth scenario, two options are suggested in order to tackle the water supply issues at the end of the planning horizon.
\end{abstract}

\section{(9) (1) CC BY: Creative Commons Attribution License 4.0}

\section{Introduction}

Water demand tends to exceed the available supply capacity, especially in many developing countries, as a result of rapid population growth (Ingeduld et al., 2006). As a consequence, Intermittent Water Supply (IWS) regimes are introduced with the aim of limiting that demand. Water scarcity in arid regions is also amplified when there is a lack of conveying capacity in the distribution network, which is too deteriorated to deliver the required demands (Ameyaw et al., 2013). Even though the water distribution should be equitable and efficient in such cases (Vairavamoorthy et al., 2008), IWS have become a norm rather than an exemption (Seetharam and Bridges, 2005), mainly due to necessity rather than the initial design (Vairavamoorthy et al., 2007).

IWS varies depending on the region and situation, ranging from a few hours per day to a few hours per week. Therefore, in order to compensate the periods of interruption, end-users need to store as much water as possible during service hours. Therefore, the water distribution is not homogenous, creating high peak factors and inadequate pressures in the distribution system (Andey and Kelkar, 2009). Consequently, the system becomes unreliable due to pumps and pipes failing to carry the required water during supply (Ameyaw et al., 2013).

Individual storage facilities, usually tanks, play important role in IWS systems, since these are the solely supply at moment of unavailability. The water inflow into each household tank relies on the pressure conditions in the network and it equals to the maximum amount of water that can be collected during the supply hours (Ingeduld $e t$ al., 2006). Therefore, water demand balance takes place for each individual household storage tank, "whereby replenishing of the volume behaves differently depending on water availability in the distribution network" (Trifunović and Abu-Madi, 1999). Furthermore, the water is consumed according to the demand patterns which are not necessarily influenced by the IWS regime, but rather by common household habits and activities.

\subsection{Case Study Description}

Tourist islands face additional pressure when tackling scarcity, while aiming to optimise the revenues from tourism and providing sufficient environmental protection at the same time. Puerto Ayora as the main tourist hub of Santa Cruz Island, has a distribution network built approximately in the 1980's, which has 2500 service connections and supplies intermittently brackish water to approximately 12,000 inhabitants (INEC, 2010). Due to the lack of proper maintenance, the network is characterized by high leakage levels whose actual figure are still not confirmed. Most premises in this town have storage facilities, mainly in the form of roof-tanks and/or cisterns, perceiving the supply as unreliable and insufficient. On the other hand, the fixed water-tariff structure seems to be the main cause of excessive water wastage within the premises. In short: the municipal supply service has not been able to cope with current tourist growth trends (Reyes Pérez, 2017). 
The aim of this paper is to analyse the performance of the current hydraulic network in Puerto Ayora, evaluating the water losses from spilling of roof tanks. During fieldwork data collection, a peculiar situation was observed regarding the overwhelming amount of wastage from the overflow of roof-tanks. The origin of this type of losses seems to be due to the absence of floating valves and the fact that the faucets are not closed when the tank is already full. Therefore, a methodology was developed for the quantification of water overflow of household-roof tanks, which further questions the currently applied IWS regime using the EPANET model. The hydraulic simulations for the current study were conducted by running the Pressure-Driven Analysis (PDA) feature of the EPANET software, while the future demand scenarios were simulated by the Demand-Driven Analysis (DDA).

\section{Demand-Driven Analysis (DDA) and Pressure-Driven Analysis (PDA)}

The default hydraulic solver for water network modelling commonly uses the Demand Driven Analysis (DDA). DDA assumes that nodal demands are known functions of time, and are independent of the available pressure in the distribution system (Cheung et al., 2005). The hydraulic solver produces the nodal pressures and pipe/pump flows which satisfy those fixed nodal demands. The DDA under regular supply conditions presents a reasonable and closeto reality solutions, assuming that the nodal demands are always delivered. The algorithm in the modelling software is able to formulate the needed equations in order to solve the unknown nodal heads (Ozger and Mays, 2003), regardless of the pressures throughout the distribution system. However, these algorithms are unable to capture precisely the how intermittent systems behave, operating under irregular conditions.

The studies developed by Germanopoulos (1985), Martinez et al. (1999), Soares et al. (2003), Hayuti and Burrows (2004) and Tanyimboh et al. (2004), discuss the restrictions of DDA. On the contrary, these studies suggest that the use of the PDA, which assumes a fixed demand above given pressure threshold, zero demand below the given minimum pressure, and proportional relationship between the pressure and the demand for the pressure range between the threshold and the minimum values is a more reliable method in irregular situations (Cheung et al., 2005). The PDA approach aims to replicate a pressure-demand relation in the modelling process, using the concept of orifices at system nodes. Consequently, the previous-mentioned studies suggest that PDA tend to be more effective than DDA at the moment of simulating intermittent water supply conditions.

Tanyimboh et al. (2001), describe the PDA relationship as follows (Reyes Pérez, 2017):

$$
H_{i}=H_{i}^{\min }+K_{i} Q_{i}^{n}
$$

(Equation 1)

where $H_{i}$ represents the actual head at demand node $i, H_{i}^{\min }$ refers to the minimum head to which below the service ends, $K_{i}$ is the resistance coefficient for node $i, Q_{i}$ refers to the nodal discharge flow, and $n$ is the exponent that theoretically and usually takes the value of 2.0 (Gupta and Bhave, 1996). Furthermore, if the value of $Q_{i}$ is unknown for any given nodal head, then Equation 8.1 needs to be rearranged as follows:

$$
Q_{i}=\left(\frac{H_{i}-H_{i}^{\min }}{K_{i}}\right)^{1 / n}
$$

(Equation 2)

If $Q_{i}$ equals the required demand, $Q_{\text {req }}, H_{i}$ should then equal the desired head in the node, named $H_{d e s}$. If the demand at that node further needs to be fully satisfied, then the head should be available as follows:

$$
Q_{i}^{r e q}=\left(\frac{H_{i}^{\text {des }}-H_{i}^{\text {min }}}{K_{i}}\right)^{1 / n} \Rightarrow \frac{1}{K_{i}^{1 / n}}=\frac{Q_{i}^{r e q}}{\left(H_{i}^{\text {des }}-H_{i}^{\min }\right)^{1 / n}}
$$

Finally, Equation 4 is obtained by substituting $\mathrm{K}_{\mathrm{i}}$ in Equation 8.2:

$$
Q_{i}^{a v l}=Q_{i}^{r e q}\left(\frac{H_{i}^{a v l}-H_{i}^{\mathrm{min}}}{H_{i}^{\text {des }}-H_{i}^{\mathrm{min}}}\right)^{1 / n}
$$

(Equation 3)

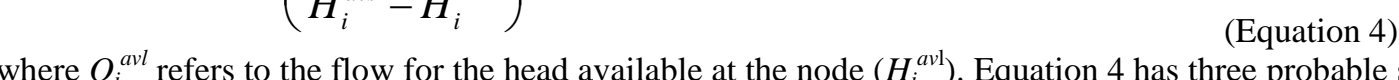

1) $H_{i}^{a v l} \leq H_{i}^{\text {min }} \Rightarrow Q_{i}^{a v l}=0$

2) $H_{i}^{\text {min }}<H_{i}^{a v l}<H_{i}^{\text {des }} \Rightarrow 0<Q_{i}^{a v l}<Q_{i}^{r e q}$

3) $H_{i}^{a v l} \geq H_{i}^{\text {des }} \Rightarrow Q_{i}^{a v l}=Q_{i}^{r e q}$

These situations are used when balancing the flows in the pipes, which are connected to node $i$. The key issue is the correct definition for $H_{i}^{\text {min }}$ and $H_{i}^{\text {des }}$, such as their correlation with the nodal resistance $K_{i}$, which is the one that describes the nature of the PDD empirical relationship.

The EPANET software, developed by Rossman (2000) uses the PDA concept through Emitter Coefficients (EC), which model pressure-dependant flows from sprinkler heads. The concept of EC is described by using similar relationships as in Equation 1. In this case, an emitter is modelled as a dummy pipe connected to the actual demand node, with a dummy reservoir whose nodal elevation $(z)$ equals the initial head. Hence, $H_{i}^{\min }=z_{i}$ and:

$$
Q_{i}=\frac{1}{K_{i}^{1 / n}}\left(H_{i}-z_{i}\right)^{1 / n}
$$


The K-value in Equation 5 refers to the resistance of the dummy pipe, but actually it has the same meaning as in Equations 1 to 3. Finally,

$$
Q_{i}=k_{i}\left(\frac{p_{i}}{\rho g}\right)^{\alpha} \quad ; \quad \frac{p_{i}}{\rho g}=H_{i}-z_{i} \quad ; \quad \alpha=1 / n \quad ; \quad k_{i}=\frac{1}{K_{i}^{\alpha}}
$$

(Equation 6)

where $k_{i}$ is the EC in node $i$ and $\alpha$ is an emitter exponent with theoretical value of 0.5. EC was first introduced to simulate operation of fire hydrants.

In order to use the PDA accurately, it is required extensive field data collection in order to determine the relationship between nodal heads and flows (Ozger and Mays, 2003). Other PDA approaches have been based on further improvement of the EC concept of the EPANET, such as the one by Pathirana (2010).

\section{Methodology}

The gravity hydraulic network model was built in the EPANET software, as shown in Figure 1, which consists of two reservoirs, 284 nodes and 367 pipes. The estimation of nodal demands was done based on the total population and an estimated demography per $\mathrm{m}^{2}$, using the demand patterns established for this particular case study found in Reyes et al. (2017b).

Figure-1. Layout of Puerto Ayora water supply network

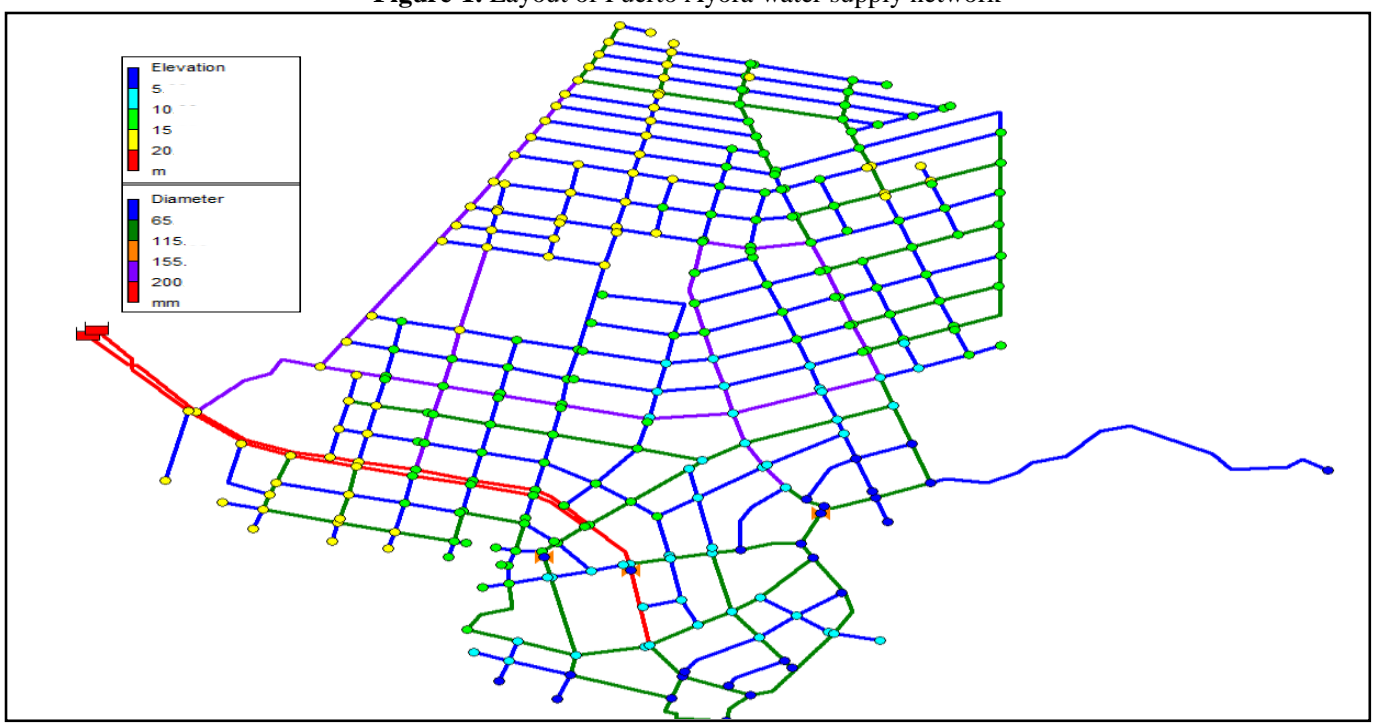

To check the numerical stability, as well as the robustness of the EPANET program, each node was modelled as being connected to a tank, which's was calculated by the number of occupants supplied at that node, and the elevation determined was that corresponding to that node; this model is shown in Figure 2. An average tank height of $1.5 \mathrm{~m}$ above the ground level average, as well as an average of five inhabitants per household was assumed. All tanks were assigned the initial depth of $1 \mathrm{~m}$, the minimum depth of $0 \mathrm{~m}$, and the maximum depth of $3 \mathrm{~m}$. Also, a check-valve was modelled with a short dummy pipe, in order to prevent backflow from the storage tank (i.e simulate the inlet arrangement from the top).

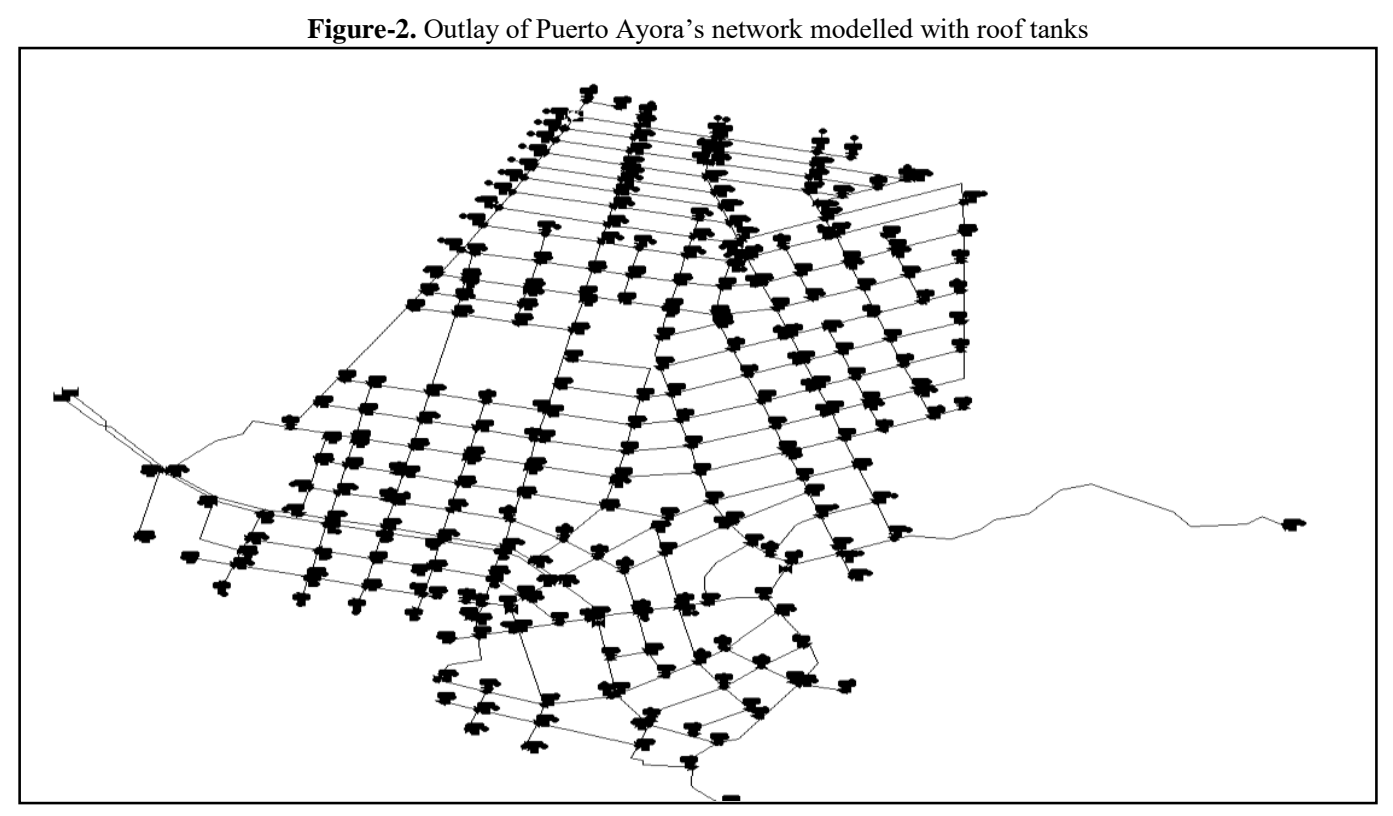


Also, as an alternative, the PDA approach was simplified in order to translate the rationing as it is applied in reality. To make this possible, the network modelled with EC was divided into five small sub-systems (Figure 3), representing each distribution zone created by the municipality. In order to match the previously reported total amount of supply per day, which is approx. $5000 \mathrm{~m}^{3}$ for the horizon 2015, including the leakage (Reyes et al., 2016), different EC values were tried for each zone and supply hours, adopting an EC value of 0.5.

Figure-3. Layouts of zones divided by distributed supply according to the Municipality of Santa Cruz (Reyes Pérez, 2017).

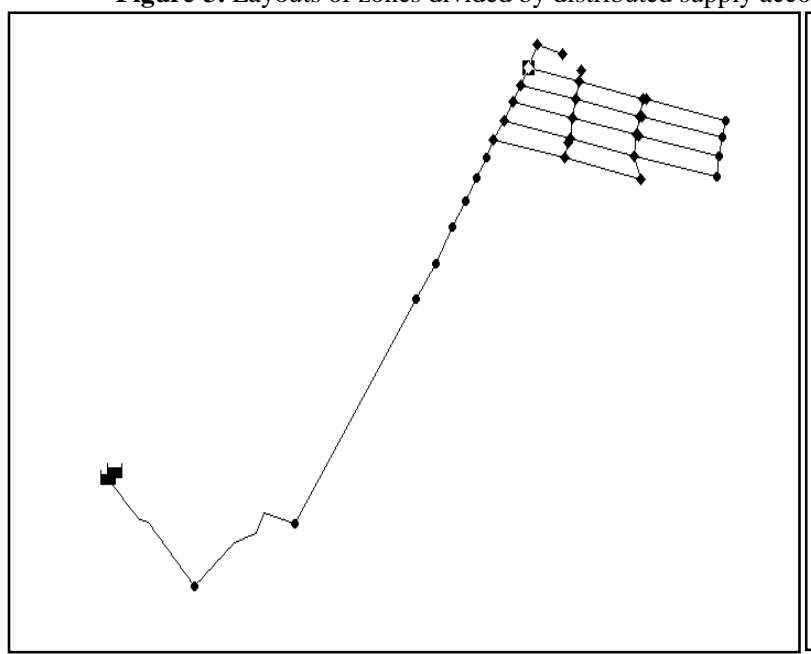

(a) - supply from 11 to13 hrs.

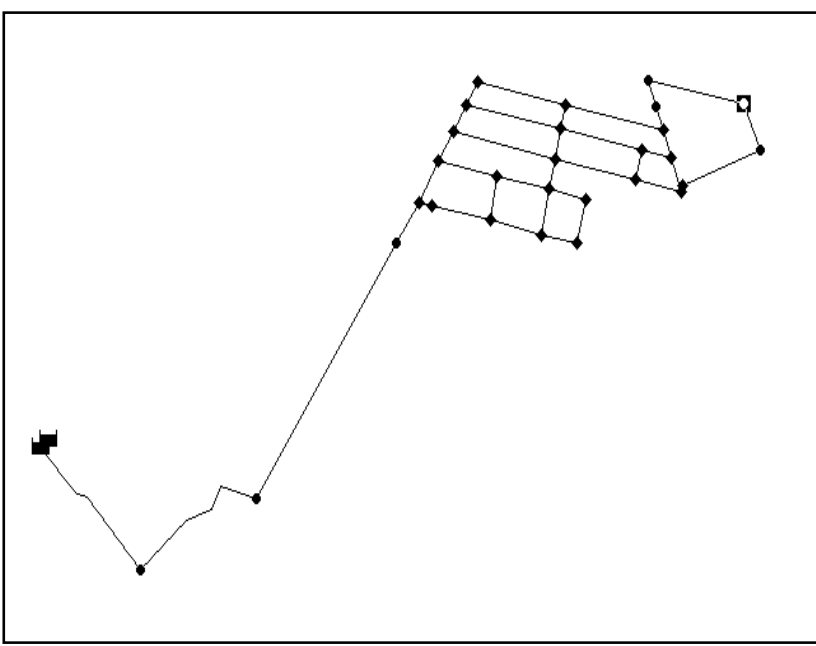

(c) - supply from 9 to 11 hrs.

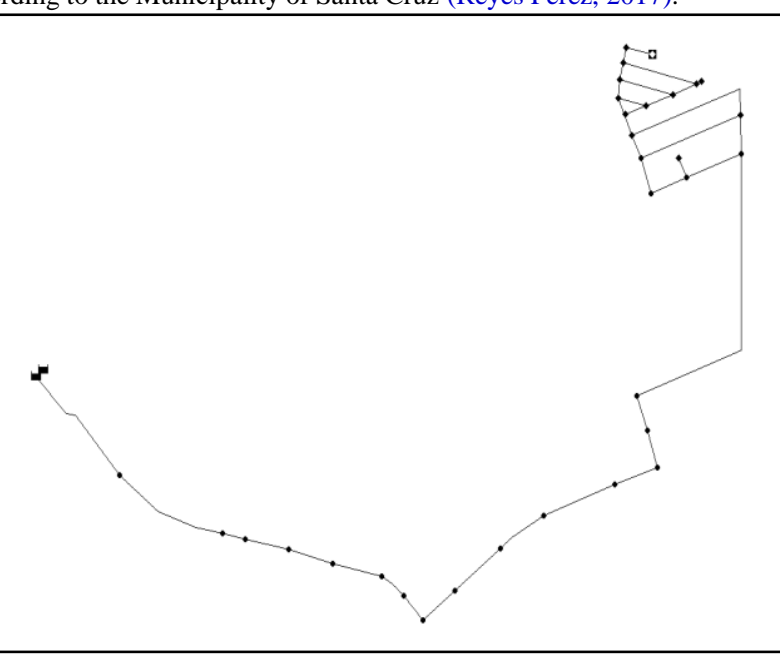

(b) - supply from 13 to $16 \mathrm{hrs}$.

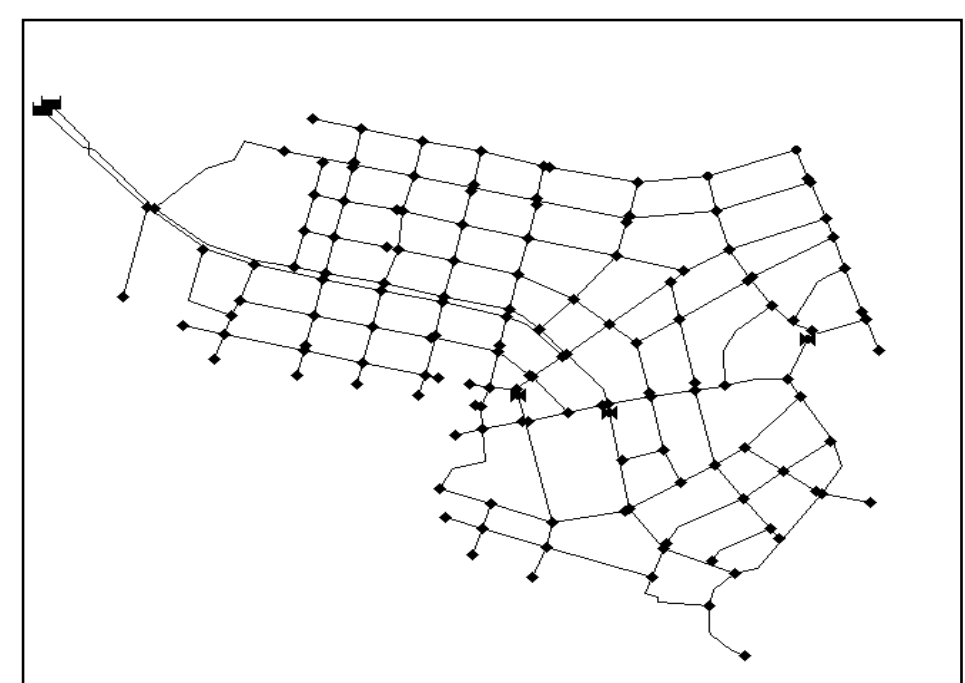

(e) - supply from 6 to 9 hrs.

The assessment of the overflow of the nodal tanks was done per zone, using several scenarios created by varying the leakage, the average volume of individual storage tanks, and the percentage of the tank level at the moment the water supply starts in a particular distribution zone. 
The volumes considered in making the balance for each node of the five sub-models are further shown in Equations 7 - 10 (Reyes Pérez, 2017).

$$
V_{i}^{a v l}=n_{h, i} X_{1}
$$

(Equation 7)

$V_{i}^{a v l}$ is the total available individual storage volume in node $i$ (in $\mathrm{m}^{3}$ ), $n_{h, i}$ is the number of households served from the node, and $X_{l}$ is the variable that indicates the average storage volume available per household $\left(\mathrm{m}^{3}\right)$.

$$
V_{i}^{c 24}=n_{c, i} X_{2}
$$

(Equation 8)

$V_{i}^{c 24}$ is the total volume consumed in node $i$ over 24 hours (in $\left.\mathrm{m}^{3}\right), n_{c, i}$ is the number of consumers served from the node, and $X_{2}$ is the variable that indicates the average specific demand per capita (lpcpd).

$$
V_{i}^{s 24}=Q_{i}^{E C} h_{i}^{s}\left(1-\frac{X_{3}}{100}\right)
$$

(Equation 9)

$V_{i}^{s 24}$ is the total volume supplied to node $i$ over 24 hours $\left(\right.$ in $\mathrm{m}^{3}$ ); this is an IWS that occurs during $h_{i}^{s}$ hours at the flow $Q_{i}^{E C}$ (in $\mathrm{m}^{3} / \mathrm{h}$ ) based on the available pressure calculated in EPANET using the emitter coefficients. $X_{3}$ is the variable that indicates the average leakage percentage in node $i$.

$$
V_{i}^{c I W S}=\sum_{j=1}^{h_{i}^{s}} \frac{V_{i}^{c 24}}{24} p f_{j, i}
$$

(Equation 10)

$V_{i}^{c I W S}$ is the total volume consumed in node $i\left(\mathrm{in}^{3}\right)$ during the IWS period of $h_{i}^{s}$ hours, at hourly peak factors $p f_{j, i}$ applied depending on the period of the day when the IWS takes place (for the diurnal patterns, see (Reyes et al., $2017 \mathrm{a})$. Hence, the actual volume accumulated in the $\operatorname{tank}(\mathrm{s})$ of node $i$ during the IWS period is $V_{i}^{s 24}-V_{i}^{\text {cIWS }}$. Assuming $X_{4}$ to be the variable that indicates the percentage of the total available volume $V_{i}^{a v l}$ already occupied at the moment when the IWS starts, the buffer of volume in the tank(s) of node $i, V_{i}^{b u f}$, when the IWS stops, will be:

$$
V_{i}^{\text {buf }}=V_{i}^{a v l}\left(1-\frac{X_{4}}{100}\right)-\left(V_{i}^{s 24}-V_{i}^{c l W S}\right)
$$

(Equation 11)

Possible negative result in Equation 11 will indicate the overflow i.e. the spilling from the $\operatorname{tank}(\mathrm{s})$ of node $i$. Furthermore, when the IWS stops, the tank(s) will be discharged for the volume $V_{i}^{c 24}-V_{i}^{c I W S}$ suggesting the initial volume before the IWS starts again to be:

$V_{i}^{a v l}-\left(V_{i}^{c 24}-V_{i}^{c l W S}\right)$, if the overflow was taking place during the IWS $\left(V_{i}^{b u f}<0\right)$;

$V_{i}^{a v l}-V_{i}^{b u f}-\left(V_{i}^{c 24}-V_{i}^{c I W S}\right)$, if the overflow was not taking place during the IWS $\left(V_{i}^{b u f} \geq 0\right)$.

In both of these cases, the result can in theory be negative, suggesting the water shortage and/or insufficient volume of the tanks. Assuming that this is not the case, some indication exists while assessing the values for $X_{4}$.

\begin{tabular}{|c|c|c|c|c|c|c|c|c|c|c|c|c|}
\hline & $\mathbf{n}_{\mathbf{c}, \mathbf{i}}$ & $\mathbf{n}_{\mathrm{h}, \mathrm{i}}$ & $\begin{array}{l}V_{i}^{a v l} \\
\left(\mathbf{m}^{3}\right) \\
\end{array}$ & $\begin{array}{l}X_{2} \\
\text { (lpcpd) }\end{array}$ & $\begin{array}{l}h_{i}^{S} \\
\text { (hours) }\end{array}$ & $\begin{array}{l}V_{i}^{c 24} \\
\left(\mathbf{m}^{3}\right) \\
\end{array}$ & $\begin{array}{l}V_{1}^{c I W S} \\
\text { (litres) }\end{array}$ & $\begin{array}{l}V_{2}^{c I W S} \\
\text { (litres) }\end{array}$ & $\begin{array}{l}Q_{i}^{E C} \\
(1 / s)\end{array}$ & $\begin{array}{l}V_{i}^{s 24} \\
\left(\mathbf{m}^{3}\right) \\
\end{array}$ & $\begin{array}{l}V_{i}^{s 24} \\
V_{i}^{c I W S}\left(\mathrm{~m}^{3}\right)\end{array}$ & $\begin{array}{l}V_{i}^{\text {buf }} \\
\left(\mathbf{m}^{3}\right) \\
\end{array}$ \\
\hline $\mathrm{J}-1$ & 31 & 6 & 6.2 & \multirow[t]{22}{*}{163} & \multirow[t]{22}{*}{2} & 5.1 & 272.9 & 351.2 & 2.1 & 12.4 & 11.7 & -5.5 \\
\hline $\mathrm{J}-2$ & 29 & 6 & 5.8 & & & 4.7 & 252.1 & 324.4 & 2.0 & 12.1 & 11.5 & -5.8 \\
\hline $\mathrm{J}-3$ & 18 & 4 & 3.6 & & & 2.9 & 157.0 & 202.1 & 2.1 & 12.5 & 12.2 & -8.6 \\
\hline $\mathrm{J}-42$ & 15 & 3 & 3.0 & & & 2.5 & 133.1 & 171.3 & 2.1 & 12.4 & 12.1 & -9.1 \\
\hline $\mathrm{J}-43$ & 27 & 5 & 5.4 & & & 4.4 & 238.1 & 306.4 & 2.0 & 11.8 & 11.3 & -5.8 \\
\hline $\mathrm{J}-44$ & 15 & 3 & 3.0 & & & 2.5 & 132.2 & 170.1 & 2.0 & 11.8 & 11.5 & -8.5 \\
\hline $\mathrm{J}-45$ & 27 & 5 & 5.3 & & & 4.3 & 233.3 & 300.2 & 2.1 & 12.5 & 11.9 & -6.6 \\
\hline $\mathrm{J}-46$ & 39 & 8 & 7.8 & & & 6.4 & 342.1 & 440.3 & 2.0 & 11.9 & 11.2 & -3.4 \\
\hline $\mathrm{J}-47$ & 23 & 5 & 4.5 & & & 3.7 & 198.8 & 255.8 & 2.1 & 12.6 & 12.1 & -7.6 \\
\hline $\mathrm{J}-48$ & 47 & 9 & 9.3 & & & 7.6 & 408.9 & 526.2 & 2.0 & 11.6 & 10.7 & -1.3 \\
\hline $\mathrm{J}-50$ & 27 & 5 & 5.4 & & & 4.4 & 238.3 & 306.7 & 1.8 & 10.5 & 10.0 & -4.5 \\
\hline $\mathrm{J}-64$ & 28 & 6 & 5.7 & & & 4.6 & 249.4 & 321.0 & 2.0 & 11.7 & 11.1 & -5.4 \\
\hline $\mathrm{J}-65$ & 54 & 11 & 10.9 & & & 8.8 & 475.7 & 612.1 & 2.1 & 12.5 & 11.4 & -0.5 \\
\hline J-66 & 27 & 5 & 5.4 & & & 4.4 & 237.6 & 305.8 & 2.1 & 12.5 & 11.9 & -6.5 \\
\hline $\mathrm{J}-67$ & 44 & 9 & 8.9 & & & 7.2 & 389.5 & 501.3 & 2.0 & 12.1 & 11.2 & -2.3 \\
\hline J-68 & 28 & 6 & 5.6 & & & 4.5 & 244.3 & 314.3 & 2.2 & 12.8 & 12.3 & -6.7 \\
\hline J-69 & 35 & 7 & 7.1 & & & 5.8 & 311.0 & 400.2 & 2.2 & 13.2 & 12.5 & -5.4 \\
\hline $\mathrm{J}-70$ & 29 & 6 & 5.8 & & & 4.7 & 254.1 & 326.9 & 2.0 & 12.1 & 11.5 & -5.7 \\
\hline J-78 & 54 & 11 & 10.8 & & & 8.8 & 473.6 & 609.4 & 2.1 & 12.7 & 11.6 & -0.8 \\
\hline J-79 & 47 & 9 & 9.3 & & & 7.6 & 407.9 & 524.9 & 2.0 & 11.8 & 10.9 & -1.6 \\
\hline $\mathrm{J}-80$ & 26 & 5 & 5.2 & & & 4.2 & 227.6 & 292.9 & 2.0 & 11.7 & 11.2 & -6.0 \\
\hline J-81 & 34 & 7 & 6.8 & & & 5.5 & 298.0 & 383.5 & 2.3 & 13.5 & 12.9 & -6.1 \\
\hline
\end{tabular}

For instance, a sample calculation done for IWS Zone 1 shown in Figure 3(a) is given in Table 1, taking $X_{1}=1.5$ $\mathrm{m}^{3}, X_{2}=163 \mathrm{lpcpd}, h_{i}^{s}=2$ hours, $X_{3}=17.5 \%, p f_{1}=1.29, p f_{2}=1.66$, and $X_{4}=0$. With these, the total overflow amounts at approximately $114 \mathrm{~m}^{3}$, which is about $42 \%$ of the total volume supplied (of $269 \mathrm{~m}^{3}$ ).

Table-1. Estimation of tanks' volumes of overflow in IWS Zone 1 
This assessment was carried out for the entire network, and the influence of each variable was further evaliated. Finally, the water supply network was assessed for the future demand under the same four tourist and local population growth scenarios used in Chapter 6 (Mena et al., 2013). The analysis was done in the intervals of five years, as shown in Table 2. The same growth rate was used for all nodal demands, while the tourist demand was distributed amongst the nodes located in the center of the town (where most of the tourist facilities are).

Table-2. Local and tourism population growth estimations for 30 years planning horizon in Puerto Ayora

\begin{tabular}{|c|c|c|c|c|c|}
\hline YEAR & $\begin{array}{l}\text { Total } \\
\text { growth } \\
\text { rate }\end{array}$ & $\begin{array}{l}\text { Local } \\
\text { population } \\
\text { (inhab.) } \\
\end{array}$ & $\begin{array}{l}\text { Demand local } \\
\text { population } \\
\text { (m3/day) }\end{array}$ & $\begin{array}{l}\text { No. of } \\
\text { tourists/ } \\
\text { year }\end{array}$ & $\begin{array}{l}\text { Tourist } \\
\text { consumption } \\
(\mathrm{m} 3 / \text { day }) \\
\end{array}$ \\
\hline \multicolumn{6}{|c|}{ SLOW GROWTH } \\
\hline 2015 & - & 15,801 & 2,576 & 205,505 & 1,109 \\
\hline 2020 & 0.05 & 16,607 & 2,707 & 215,780 & 1,165 \\
\hline 2025 & 0.10 & 17,454 & 2,845 & 226,055 & 1,220 \\
\hline 2030 & 0.15 & 18,345 & 2,990 & 236,331 & 1,276 \\
\hline 2035 & 0.20 & 19,280 & 3,143 & 246,606 & 1,331 \\
\hline 2040 & 0.25 & 20,264 & 3,303 & 256,881 & 1,386 \\
\hline 2045 & 0.30 & 21,087 & 3,437 & 267,156 & 1,442 \\
\hline \multicolumn{6}{|c|}{ MODERATE GROWTH } \\
\hline 2015 & - & 15,801 & 2,576 & 205,505 & 1,109 \\
\hline 2020 & 0.15 & 18,318 & 2,986 & 236,331 & 1,276 \\
\hline 2025 & 0.30 & 21,235 & 3,461 & 267,156 & 1,442 \\
\hline 2030 & 0.45 & 24,618 & 4,013 & 297,982 & 1,608 \\
\hline 2035 & 0.60 & 28,539 & 4,652 & 328,808 & 1,775 \\
\hline 2040 & 0.75 & 33,084 & 5,393 & 359,634 & 1,941 \\
\hline 2045 & 0.90 & 37,236 & 6,070 & 390,459 & 2,107 \\
\hline \multicolumn{6}{|c|}{ FAST GROWTH } \\
\hline 2015 & - & 15,801 & 2,576 & 205,505 & 1,109 \\
\hline 2020 & 0.25 & 20,167 & 3,287 & 256,881 & 1,386 \\
\hline 2025 & 0.50 & 25,738 & 4,195 & 308,257 & 1,664 \\
\hline 2030 & 0.75 & 32,849 & 5,354 & 359,634 & 1,941 \\
\hline 2035 & 1.00 & 41,925 & 6,834 & 411,010 & 2,218 \\
\hline 2040 & 1.25 & 53,508 & 8,722 & 462,386 & 2,496 \\
\hline 2045 & 1.50 & 65,040 & 10,601 & 513,762 & 2,773 \\
\hline \multicolumn{6}{|c|}{ VERY FAST GROWTH } \\
\hline 2015 & - & 15,801 & 2,576 & 205,505 & 1,109 \\
\hline 2020 & 0.35 & 22,174 & 3,614 & 277,432 & 1,497 \\
\hline 2025 & 0.70 & 31,116 & 5,072 & 349,358 & 1,886 \\
\hline 2030 & 1.05 & 43,665 & 7,117 & 421,285 & 2,274 \\
\hline 2035 & 1.40 & 61,275 & 9,988 & 493,212 & 2,662 \\
\hline 2040 & 1.75 & 85,987 & 14,016 & 565,139 & 3,050 \\
\hline 2045 & 2.10 & 112,759 & 18,380 & 637,065 & 3,438 \\
\hline
\end{tabular}

\section{Modelling, Results and Discussion}

\subsection{Current Situation Simulated with Nodal Tanks}

The fist simulation was conducted with the network model shown in Figure 2. This model indicates 578 nodes, 286 tanks and 940 pipes. The latter originates from the setup of the discharge from the tanks that consists of a dummy pipe attached to the node with a consumption pattern, and another dummy pipe on the upstream side of each tank, representing a check-valve; shown in Figure 4. The model setup becomes rather bulky; however it is the only way to reflect the actual reality.

After several attempts, the simulation runs did not presented any tangible result. First of all, the model appeared to be very sensitive to the selection of the tank properties and the initial water levels. As soon as the tank gets emptied or filled from the imbalance between the demand and supply, based on the EPANET settings, the tank becomes disconnected from the network. This suggests that this inflicts numerical instability, which was also experienced by significantly longer simulation times than usual, and resulting in negative pressures in the network.

Figure 4 shows the documented negative pressures in the model, while Figure 5 shows the trends of water level variation in randomly selected tanks in the same distribution area. 
Figure-4. Layout of Puerto Ayora's network with nodal tanks

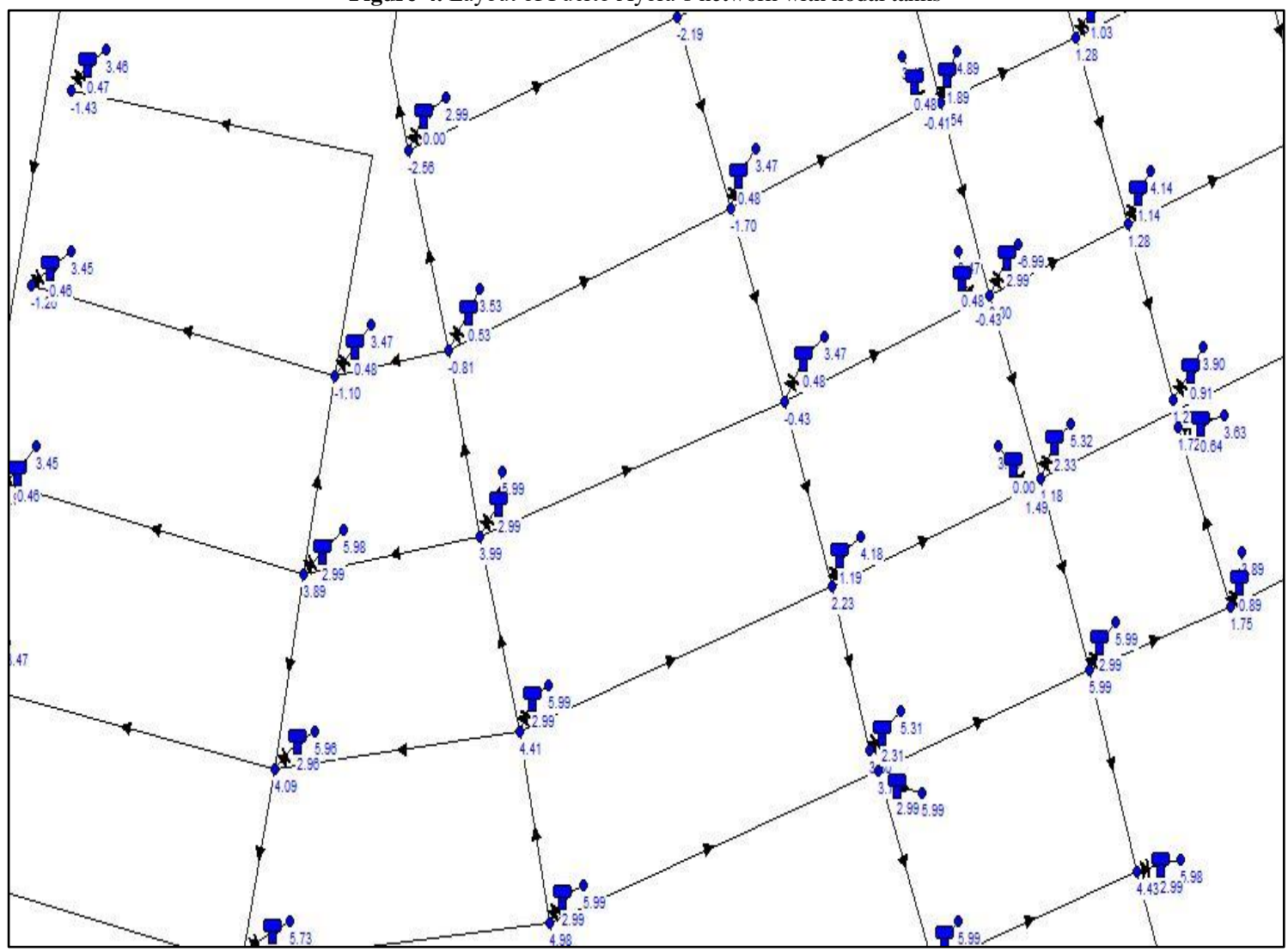

Figure-5. Pressures over 24 hours for randomly selected tanks

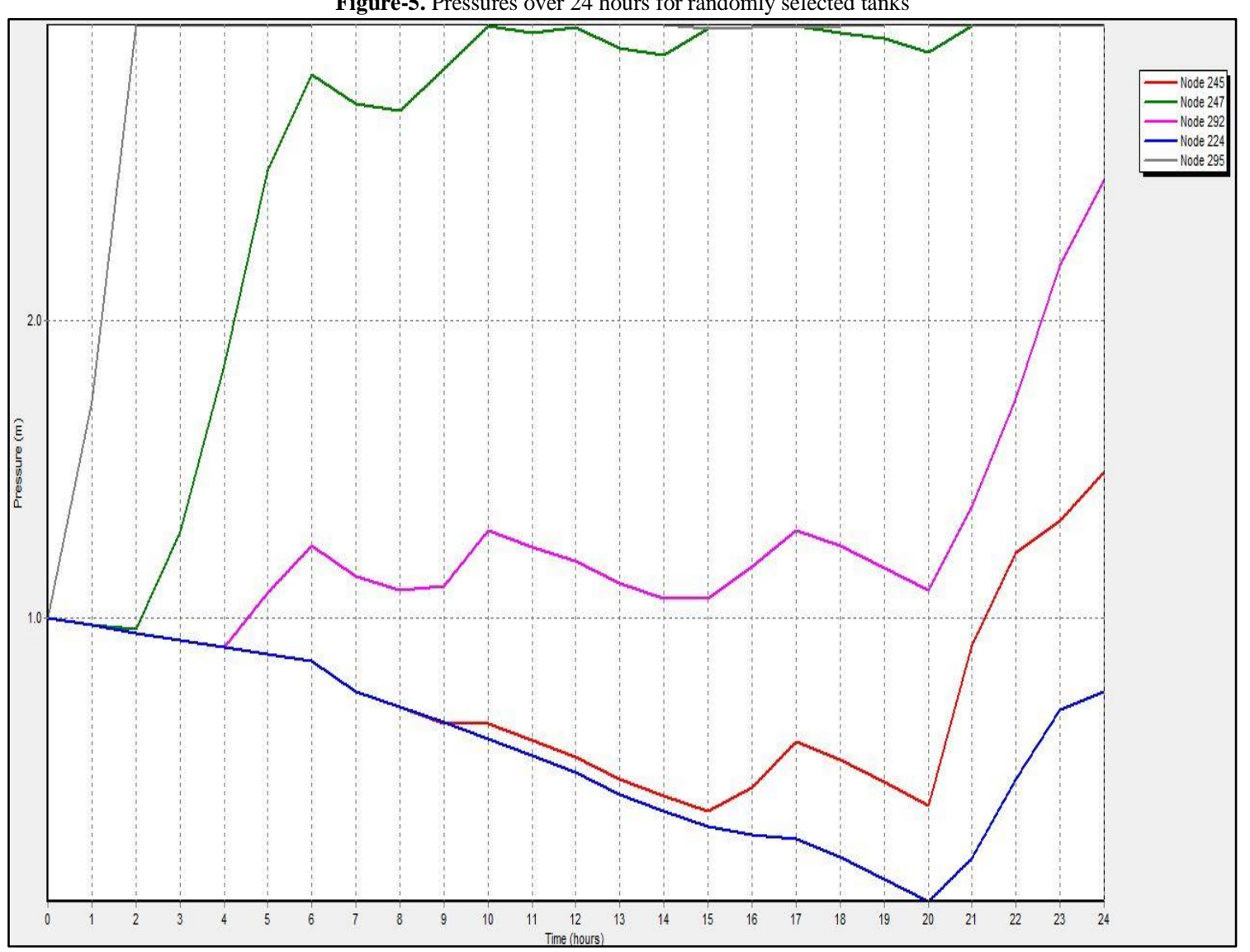

Therefore, the calibration of such a model appeared to be very complex and it suggested that the amount of tanks influenced somehow; the model could work only if these are not entirely emptied or completely full. The model becomes unstable and might only work if all the tanks have sufficient amount of water throughout the entire day. In that case, analyses of irregular water distribution schemes become very challenging, and the other approach was tested. 


\subsection{Results of Pressure-Driven Approach with Emitter Coefficients}

The alternative way of modelling was therefore adopted using the approach illustrated by Equations 7 to 11 and in Table 1. The 16 selected scenarios based on the values $X_{1}$ to $X_{4}$ and the results showing the buffer volume are shown in Table 3. Two specific demand scenarios $\left(X_{2}\right)$ correspond to the figures obtained by the field survey described in Reyes et al. (2017b). Similarly, the leakage scenarios $\left(X_{3}\right)$ were set by assuming the physical leakage to be $50 \%$ of the total NRW levels (assessed at 35 and 50\%, respectively). The negative buffer indicates the spilling from the tanks with the $2^{\text {nd }}$ figure showing the value reduced for $30 \%$, which is believed to be the percentage of the households having the float valves installed on their roof tanks.

Table-3. Scenarios for the estimate of tank overflows in Puerto Ayora

\begin{tabular}{|c|c|c|c|c|c|c|}
\hline $\begin{array}{l}X_{2} \\
\text { (lpcpd) }\end{array}$ & $\begin{array}{l}X_{3} \\
(\%)\end{array}$ & $\begin{array}{l}X_{1} \\
\left(\mathbf{m}^{3}\right)\end{array}$ & $\begin{array}{l}X_{4} \\
(\%)\end{array}$ & $\begin{array}{l}V_{i}^{\text {buf }} \\
\left(\mathbf{m}^{3}\right)\end{array}$ & $\begin{array}{l}V_{i}^{\text {buf }}(2) \\
\left(\mathrm{m}^{3}\right)\end{array}$ & $\%$ total daily supply \\
\hline \multirow[t]{16}{*}{163} & \multicolumn{6}{|c|}{ Scenario 1} \\
\hline & 17.5 & 1 & 0 & -1327 & -929 & 18.6 \\
\hline & \multicolumn{6}{|c|}{ Scenario 2} \\
\hline & 17.5 & 1 & 50 & -2301 & -1611 & 32.2 \\
\hline & \multicolumn{6}{|c|}{ Scenario 3} \\
\hline & 17.5 & 2 & 0 & -423 & -296 & 5.9 \\
\hline & \multicolumn{6}{|c|}{ Scenario 4} \\
\hline & 17.5 & 2 & 50 & -709 & -496 & 9.9 \\
\hline & \multicolumn{6}{|c|}{ Scenario 5} \\
\hline & 25 & 1 & 0 & -1053 & -737 & 14.7 \\
\hline & \multicolumn{6}{|c|}{ Scenario 6} \\
\hline & 25 & 1 & 50 & -1957 & -1370 & 27.4 \\
\hline & \multicolumn{6}{|c|}{ Scenario 7} \\
\hline & 25 & 2 & 0 & -287 & -201 & 4.0 \\
\hline & \multicolumn{6}{|c|}{ Scenario 8} \\
\hline & 25 & 2 & 50 & -1053 & -737 & 14.7 \\
\hline \multirow[t]{16}{*}{195} & \multicolumn{6}{|c|}{ Scenario 9} \\
\hline & 17.5 & 1 & 0 & -1285 & -900 & 18.0 \\
\hline & \multicolumn{6}{|c|}{ Scenario 10} \\
\hline & 17.5 & 1 & 50 & -2239 & -1567 & 31.3 \\
\hline & \multicolumn{6}{|c|}{ Scenario 11} \\
\hline & 17.5 & 2 & 0 & -411 & -287 & 5.7 \\
\hline & \multicolumn{6}{|c|}{ Scenario 12} \\
\hline & 17.5 & 2 & 50 & -1285 & -900 & 18.0 \\
\hline & \multicolumn{6}{|c|}{ Scenario 13} \\
\hline & 25 & 1 & 0 & -1016 & -712 & 14.2 \\
\hline & \multicolumn{6}{|c|}{ Scenario 14} \\
\hline & 25 & 1 & 50 & -1900 & -1330 & 26.6 \\
\hline & \multicolumn{6}{|c|}{ Scenario 15} \\
\hline & 25 & 2 & 0 & -298 & -208 & 4.2 \\
\hline & \multicolumn{6}{|c|}{ Scenario 16} \\
\hline & 25 & 2 & 50 & -1016 & -712 & 14.2 \\
\hline
\end{tabular}

In terms of the percentage of daily supply, the results show a wide range between 4.2 and $32.2 \%$, which indicates sensitive input data. Based on the field observations at the case study area, it is believed that Scenario 6 may be the closest to the reality, with remark that the tank levels at the beginning of the IWS next day may vary in filling percentages, which depends on the consumption pattern of the previous day; hence, the values of $X_{4}$ need specific validation compared to the other three variables.

Based on the results in Table 3, an assessment carried out to calculate the additional supply in case the overflow from the tanks could have been prevented. Table 4 shows the additional population that could be supplied for each of the 16 chosen scenarios, assuming two specific demands used in the analysis of the tank buffers. As can be observed, in the most extreme situation of Scenario 2, almost $60 \%$ of additional population could have been supplied at the lower specific demand of $163 \mathrm{lpcpd}$, and nearly 50\% at the higher one of $195 \mathrm{lpcpd}$. These results put a valid hypothesis about the actual necessity of the roof tanks, since they may not be easing the current intermittent situation, but actually boosting it, resulting from the negligence of local population. 
Table-4. Additional population to be supplied based on different overflow scenarios

\begin{tabular}{l|l|l|l|l}
\hline Scenarios & $\begin{array}{l}\text { Specific Demand } \\
\text { of 163 lpcpd }\end{array}$ & $\begin{array}{l}\text { Percentage of } \\
\text { population }\end{array}$ & $\begin{array}{l}\text { Specific Demand } \\
\text { of 195 lpcpd }\end{array}$ & $\begin{array}{l}\text { Percentage of } \\
\text { population }\end{array}$ \\
\hline 1 & 5697 & 33.5 & 4762 & 28.0 \\
\hline 2 & 9882 & 58.1 & 8261 & 48.6 \\
\hline 3 & 1817 & 10.7 & 1519 & 8.9 \\
\hline 4 & 3043 & 17.9 & 2543 & 15.0 \\
\hline 5 & 4521 & 26.6 & 3779 & 22.2 \\
\hline 6 & 8403 & 49.4 & 7024 & 41.3 \\
\hline 7 & 1234 & 7.3 & 1032 & 6.1 \\
\hline 8 & 4521 & 26.6 & 3779 & 22.2 \\
\hline 9 & 5519 & 32.5 & 4614 & 27.1 \\
\hline 10 & 9614 & 56.6 & 8036 & 47.3 \\
\hline 11 & 1763 & 10.4 & 1474 & 8.7 \\
\hline 12 & 5519 & 32.5 & 4614 & 27.1 \\
\hline 13 & 4365 & 25.7 & 3649 & 21.5 \\
\hline 14 & 8158 & 48.0 & 6819 & 40.1 \\
\hline 15 & 1278 & 7.5 & 1068 & 6.3 \\
\hline 16 & 4365 & 25.7 & 3649 & 21.5 \\
\hline Source: (Reyes Pérez, 2017) & &
\end{tabular}

The sensitivity of the four $X$-variables was further analysed against the tank overflow in somewhat wider range than the one applied in the 16 scenarios. Figure 6 shows that the highest sensitivity belong to the variables $X_{1}$ and $X_{4}$, which underpins the need for further fieldwork in order to validate the available volume (individual household storage), and the initial level of the tanks before the IWS kicks-off every day. On the other hand, the specific demand, as well as the average leakage percentage, influence the overflow volume to a lesser extent.

Figure-6. Sensitivity analysis based on different (a) individual tank volume, (b) specific demand, (c) leakage level and (d) tank level in total overflow estimation
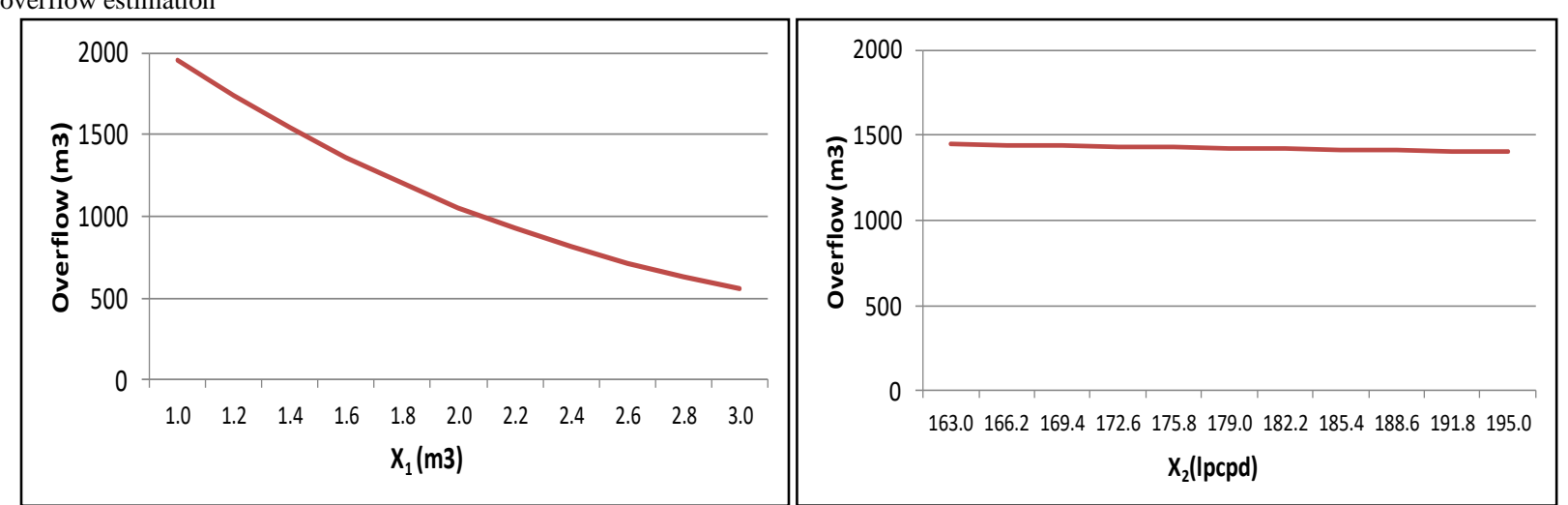

(a)

(b)
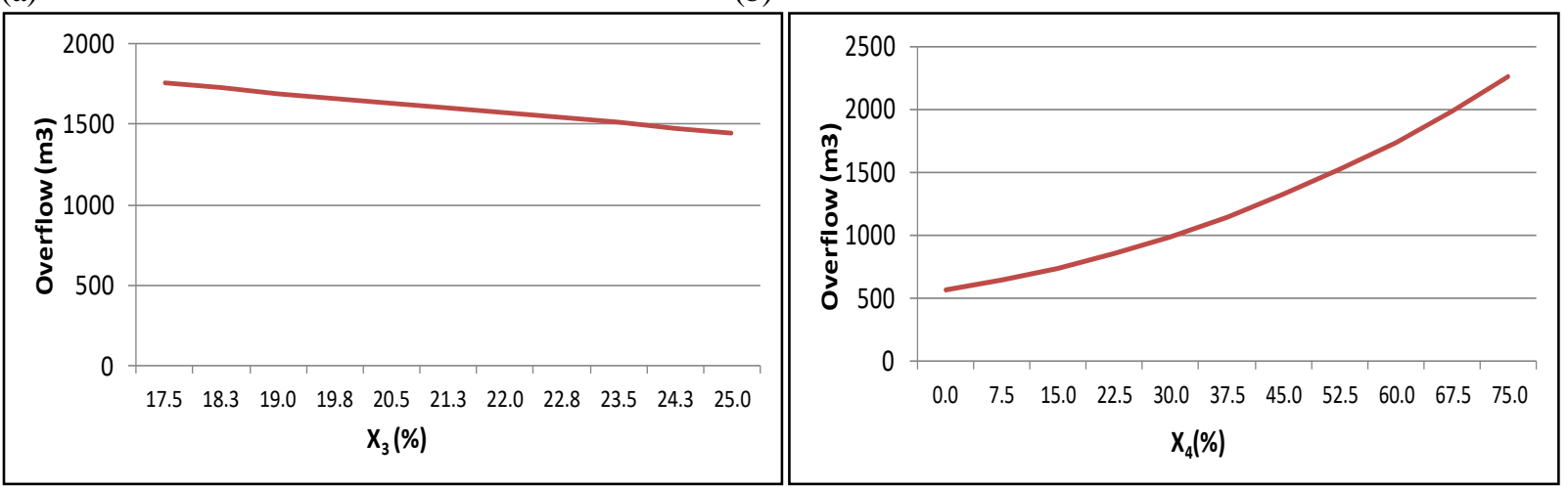

(c)

(d)

\section{Conclusions}

Three modelling approaches illustrated in this paper, included nodal tanks, the PDA and the DDA, for the current demand in Puerto Ayora. In the first case, it was very complicated to replicate the actual individual storage in the model. The EPANET software becomes unstable due to different water level patterns in each tank, sometimes full and sometimes empty. More detailed information would be needed for a proper calibration of such a model but even then it is possibly that the model could perform only regular demand scenarios. Unfortunately, EPANET disconnects empty tanks which distorts its numerical stability in multiple occurrence of this situation. 
The PDA of present demand reflects partially the situation with the household storages. The aim was to estimate the overflow of roof tanks under several scenarios. As observed from the results, it can be concluded that there may be a significant amount of water lost due to the overflow of the roof tanks. The local authorities in Puerto Ayora, as well as local residents, have the erroneous idea of the "need" for individual storage to compensate the lack of water in the hours of no supply, which to the large extent may result from the negligence.

The sensitivity analysis suggests which input data should be verified with priority. The result show the size of individual household tanks and the initial level when the supply begins have more impact on the overflow, than the leakage percentage or per capita demand. Despite the fact that many assumptions were made, this analysis provides a practical approach to measure the volume that might be spilled from household tanks, which seems to be the main source of water wastage. The municipality would need to monitor and record individual characteristics of the households' storage facilities, in order to assess more accurately the extent of this problem. Also, the model should be further calibrated by adequate choice of emitter coefficients.

Finally, the research points that the hydraulic modelling of distribution networks in tourist islands poses quite a complex problem due to: (1) numerical instability caused by multiple tanks existing in the model, and (2) difficult calibration from lots of unknown and inaccurate data needed to build a reliable model.

\section{References}

Ameyaw, E. E., Memon, F. A. and Bicik, J. (2013). Improving equity in intermittent water supply systems. Journal of Water Supply: Research and Technology-AQUA, 62(8): 552-62.

Andey, S. P. and Kelkar, P. S. (2009). Influence of intermittent and continuous modes of water supply on domestic water consumption. Water Resources Management, 23(12): 2555-66.

Cheung, P., Van Zyl, J. and Reis, L. (2005). Extension of EPANET for pressure driven demand modeling in water distribution system. Computing and Control for the Water Industry, 1(1): 311-16.

Germanopoulos, G. (1985). A technical note on the inclusion of pressure dependent demand and leakage terms in water supply network models. Civil Engineering Systems, 2(3): 171-79.

Gupta, R. and Bhave, P. R. (1996). Comparison of methods for predicting deficient-network performance. Journal of Water Resources Planning and Management, 122(3): 214-17.

Hayuti, M. and Burrows, R., 2004. "Sequential solution seeking dda based hda (sss-dda/hda) approach." In Proc. of Decision Support in the Water Industry under Conditions of Uncertainty-ACTUI 2004.

INEC, 2010. "Censo de población y vivienda del ecuador 2010." In Ecuador, Instituto Nacional de Estadísticas y Censos.

Ingeduld, P., Svitak, Z., Pradhan, A. and Tarai, A., 2006. "Modelling intermittent water supply systems with EPANET." In 8th Annual Water Distribution Systems Analysis Symposium, Cincinnati.

Martinez, F., Signes, M., Savall, R., Andrés, M., Ponz, R. and Conejos, P. (1999). Construction and use of dynamic simulation model for the valencia metropolitan water supply and distribution network. Water Industry Systems: Modeling and Optimization Applications, In: Savic, DA and Walters, GA. 1: 155-74.

Mena, C., Walsh, S., Pizzitutti, F., Reck, G., Rindfuss, R., Toral-Granda, V. D. O., Valle, C., Quiroga, D., García, J., Vasconez, L., Guevara, A., Sanchez, M., Frizelle, B. and Tippett, R. (2013). Determination of social, environmental and economical relations which allow the development based on different processes of modeling, potential scenarios of sustainability of the socio ecological system of the Galapagos Islands with emphasis on the dynamic of the flux of tourist visitors. Ministry of Environment and Galapagos National Park. 1: Galapagos.

Ozger, S. S. and Mays, L., 2003. "A semi-pressure-driven approach to reliability assessment of water distribution networks." In Proceedings of the Thirtieth Congress.

Pathirana, A., 2010. "EPANET2 desktop application for pressure driven demand modeling." In In Water Distribution Systems Analysis 2010. pp. 65-74.

Reyes, Trifunović, N., Sharma, S. and Kennedy, M. (2016). Data assessment for water demand and supply balance on the island of santa cruz (galápagos Islands). Desalination and Water Treatment, 57(45): 21335-49.

Reyes, Trifunović, N., Sharma, S. and Kennedy, M. D. (2017a). Assessment of domestic consumption in intermittent water supply networks: Case study of Puerto Ayora (Galápagos Islands). Journal of Water Supply: Research and Technology-Aqua, 55(8): 673-83.

Reyes, Trifunovic, N., d'Ozouville, N., Sharma, S. and Kennedy, M. (2017b). Quantification of urban water demand in the island of santa cruz (galápagos archipelago). Desalination and Water Treatment, 64(1): 1-11.

Reyes Pérez, M. F. (2017). Water supply and demand management in the galápagos: A case study of. CRC Press: Santa Cruz Island.

Rossman, L. A. (2000). EPANET 2: Users manual. Available: https://www.microimages.com/documentation/Tutorials/Epanet2UserManual.pdf

Seetharam, K. and Bridges, G., 2005. "Helping India achieve 24x7 water supply service by 2010." In Roundtable discussion on private sector participation in water supply in India. pp. 15-16.

Soares, A. K., Reis, L. F. R. and Carrijo, I. B., 2003. "Head-driven simulation model (HDSM) for water distribution system calibration. Advances in Water Supply Management." In Proceedings of the ccwi '03 conference, london, 15-17 september 2003. pp. 197-207.

Tanyimboh, T., Tabesh, M. and Burrows, R. (2001). Appraisal of source head methods for calculating reliability of water distribution networks. Journal of Water Resources Planning and Management, 127(4): 206-13. 
Tanyimboh, T., Walters, G., Savic, D., Khoo, S. T. and King, R., 2004. "Availability of water in distribution systems. In Decision support in the water industry under conditions of uncertainty." In Proceedings of the 2004 EPSRC ACTUI network international seminar. pp. 159-64.

Trifunović, N. and Abu-Madi, M. O. R., 1999. "Demand modelling of networks with individual storage." In In WRPMD'99: Preparing for the 21st Century. pp. 1-10.

Vairavamoorthy, K., Gorantiwar, S. D. and Mohan, S. (2007). Intermittent water supply under water scarcity situations. Water International, 32(1): 121-32.

Vairavamoorthy, K., Gorantiwar, S. D. and Pathirana, A. (2008). Managing urban water supplies in developing countries-Climate change and water scarcity scenarios. Physics and Chemistry of the Earth, Parts $A / B / C$, 33(5): 330-39. 